\title{
Infant Nasopharyngeal Microbiota Subphenotypes and Early Childhood Lung Function: Evidence from a Rural Ghanaian Pregnancy Cohort
}

\author{
Kathryn Dubowski ${ }^{1, *}$, Seyram Kaali ${ }^{2}$, Darby Jack ${ }^{3}$, Rebecca Kyerewaa Dwommoh Prah ${ }^{2}$, Jose C. Clemente ${ }^{4}$, \\ Theresa Tawiah ${ }^{2} \mathbb{D}$, Mohammed Mujtaba ${ }^{2} \mathbb{D}$, Louisa Iddrisu ${ }^{2}$, Daniel Carrión ${ }^{5} \mathbb{D}$, Dennis Gyasi Konadu ${ }^{2}$, \\ Oscar Agyei ${ }^{2}$, Francis Mensah Kornu ${ }^{2}$, Samuel Osei-Owusu ${ }^{2}$, Alison G. Lee ${ }^{1,+}$ and Kwaku Poku Asante ${ }^{2, \dagger}$
}

check for updates

Citation: Dubowski, K.; Kaali, S.; Jack, D.; Prah, R.K.D.; Clemente, J.C.; Tawiah, T.; Mujtaba, M.; Iddrisu, L.; Carrión, D.; Konadu, D.G.; et al. Infant Nasopharyngeal Microbiota Subphenotypes and Early Childhood Lung Function: Evidence from a Rural Ghanaian Pregnancy Cohort. Int. J. Environ. Res. Public Health 2021, 18, 7276. https://doi.org/10.3390/ ijerph18147276

Academic Editors: Maria E. Di Cicco, Amelia Licari and Pasquale Comberiati

Received: 14 May 2021

Accepted: 25 June 2021

Published: 7 July 2021

Publisher's Note: MDPI stays neutra with regard to jurisdictional claims in published maps and institutional affiliations.

Copyright: (C) 2021 by the authors Licensee MDPI, Basel, Switzerland. This article is an open access article distributed under the terms and conditions of the Creative Commons Attribution (CC BY) license (https:// creativecommons.org/licenses/by/ $4.0 /)$.
1 Division of Pulmonary, Critical Care and Sleep Medicine, Icahn School of Medicine Mount Sinai, New York, NY 10029, USA; Alison.Lee@mssm.edu

2 Kintampo Health Research Centre, Kintampo 00233, Ghana; kaali.seyram@kintampo-hrc.org (S.K.); rebecca.dwommoh@gmail.com (R.K.D.P.); theresa.tawiah@kintampo-hrc.org (T.T.); mohammed.mujtaba@kintampo-hrc.org (M.M.); louisa.iddrisu@kintampo-hrc.org (L.I.); dennis.konadu@kintampo-hrc.org (D.G.K.); oscar.agyei@kintampo-hrc.org (O.A.); Francis.Kornu@kintampo-hrc.org (F.M.K.); samuel.osei-owusu@kintampo-hrc.org (S.O.-O.); kwakupoku.asante@kintampo-hrc.org (K.P.A.)

3 Department of Environmental Health Sciences, Columbia University Mailman School of Public Health, New York, NY 10032, USA; dj2183@cumc.columbia.edu

4 Department of Genetics and Genomic Sciences and Medicine, Icahn School of Medicine Mount Sinai, New York, NY 10029, USA; jose.clemente@mssm.edu

5 Department of Environmental Health Sciences, Icahn School of Medicine Mount Sinai, New York, NY 10029, USA; daniel.carrion@mssm.edu

* Correspondence: kathryn.dubowski@mountsinai.org

+ Denotes Co-senior authors.

Abstract: Early life respiratory microbiota may increase risk for future pulmonary disease. Associations between respiratory microbiota and lung health in children from low- and middle-income countries are not well-described. Leveraging the Ghana Randomized Air Pollution and Health Study (GRAPHS) prospective pregnancy cohort in Kintampo, Ghana, we collected nasopharyngeal swabs in 112 asymptomatic children aged median 4.3 months (interquartile range (IQR) 2.9, 7.1) and analyzed 22 common bacterial and viral pathogens with MassTag polymerase chain reaction (PCR). We prospectively followed the cohort and measured lung function at age four years by impulse oscillometry. First, we employed latent class analysis (LCA) to identify nasopharyngeal microbiota (NPM) subphenotypes. Then, we used linear regression to analyze associations between subphenotype assignment and lung function. LCA suggest that a two-class model best described the infant NPM. We identified a higher diversity subphenotype $(\mathrm{N}=38,34 \%)$ with more pathogens (median 4 ; IQR 3.25, 4.75) and a lower diversity subphenotype $(\mathrm{N}=74,66 \%)$ with fewer pathogens (median 1 ; IQR 1, 2). In multivariable linear regression models, the less diverse NPM subphenotype had higher small airway resistance (R5-R20 $\beta=17.9 \%, 95 \%$ CI 35.6, 0.23; $p=0.047$ ) compared with the more diverse subphenotype. Further studies are required to understand the role of the microbiota in future lung health.

Keywords: nasopharyngeal microbiota; impulse oscillometry; global health

\section{Introduction}

Impairment in early childhood lung development has implications for respiratory morbidity and mortality over the life course. Poor lung function has been associated with respiratory illness, including pneumonia, a leading cause of morbidity and mortality in children worldwide and especially in low- and middle-income countries (LMICs) [1-3]. Cohort studies suggest that lower lung function by six years of age or earlier is associated 
with lower lung function in adulthood [4,5]. Decrements in early life lung function may represent structural changes that persist into adulthood thereby increasing risk for future chronic respiratory disease such as chronic obstructive pulmonary disease [5-13]. A critical step in understanding lifelong risk is characterizing mechanisms that lead to and maintain this early predisposition.

Emerging literature, mainly from high-income countries with very limited data from LMICs, is beginning to elucidate the importance of the respiratory microbiome on lung development. The respiratory tract serves as a rich environment for microbial-host interactions. A diverse respiratory microbiome is present within hours of birth and evolves dramatically from birth to age 3 years [14-18]. In high-income countries, repeated upper respiratory tract microbiome analyses suggest that tightly-orchestrated compositional changes in early childhood are influenced by environmental factors, such as tobacco smoke exposure, and individual-level factors, such as mode of delivery and parity $[19,20]$. The upper airway microbiome of healthy children provides a reasonable surrogate for the lower airway microbiome, supporting methodologies that leverage noninvasive nasal sampling of healthy children to investigate associations with early life lung health [21].

Dysbiosis, or alterations in microbe colonization of the upper airway, has been associated with respiratory disease. Disruptions in microbiome maturation may lead to airway inflammation [22], chronic wheeze and asthma [20,23,24], and pneumonia [15,25,26]. Specifically, Cornebacteriacae and Staphylococcus species which are earlier colonizers of the respiratory tract, may decrease risk for childhood wheeze and asthma [16]. Streptococcus, Haemophilus, and Moraxella species tend to colonize the respiratory tract later in development. However, when they appear earlier, they are often associated with increased risk of wheeze and the development of asthma $[19,20,24]$. Data from our cohort in rural Ghana suggests a possible link between early life colonization with bacterial pathogens, specifically Streptococcus pneumonia, Haemophilus influenza, Moraxella cattarhalis, and infant pneumonia [27]. It is unknown whether pathogen colonization is linked to other objective measures of future lung health, such as lung function.

The overall microbiome diversity may correlate with lung function and subsequent respiratory illness. Loss of diversity has been associated with increased incidence of disease and disease severity in multiple respiratory illnesses [28]. For example, loss of nasal microbiome diversity was associated with increased risk for rhinitis in infants in Singapore and asthma in children from five rural areas in Europe [16,29]. Animal studies support these associations and suggest a role of early life respiratory microbiome on lung development. For example, germ-free mice have fewer alveoli and smaller lungs; colonization with Lactobacillus spp. normalizes alveolar numbers [30,31]. Ovalbumin sensitized germ-free mice demonstrate increased airway resistance; reconstitution of microbiota at birth reverses these findings. As microbes do not exist in isolation, an understanding of subphenotypes of pathogens may be necessary to understand how the respiratory microbiome shapes lung development.

Multiple techniques for investigating the microbiome have been presented in the literature, including $16 \mathrm{~S}$ ribosomal RNA gene sequencing and shotgun metagenomics gene sequencing, and whole-genome sequencing [32,33]. These methods allow for culture independent examination of the microbiome with varying levels of specificity. Alternatively, polymerase chain reaction (PCR), a culture independent technique which detects pre-specified organisms, providing a sample of the microbiota of the lung, but not a comprehensive assessment of the microbiome [34]. This technique has also been used in the literature to explore respiratory microbiota [21]. 
To our knowledge, the role of respiratory microbiota subphenotypes on lung function has not been fully elucidated in a rural, sub-Saharan population. We therefore leveraged a pregnancy cohort from Kintampo, Ghana, to examine the relationship between infant nasopharyngeal bacterial and viral carriage as defined by PCR and early childhood lung function. Specifically, we employed latent class analysis to determine subphenotypes of bacterial and viral carriage in infancy. We then used linear regression to understand associations between the identified subphenotypes and lung function at child age four years as measured by impulse oscillometry (IOS).

\section{Materials and Methods}

\subsection{Study Participants}

Mother-infant dyads were recruited from a pregnancy cohort derived from the Ghana Randomized Air Pollution and Health Study (GRAPHS) with ongoing, prospective follow up through child age four years. The GRAPHS cohort has been described elsewhere [35]. Briefly, pregnant nonsmoking women were recruited prior to ultrasoundconfirmed 24 weeks of gestation. Key individual and household level data were collected on enrollment, including maternal age, parity, ethnicity, and number of people living in the household. Fieldworkers trained in the World Health Organization's Integrated Management of Childhood Illness (IMCI) performed weekly surveillance of study children over the first year of life and referred any child meeting criteria for pneumonia or who was otherwise unwell for physician evaluation and pneumonia diagnosis. Nasopharyngeal microbiota (NPM) swabs were collected for children with physician-diagnosed pneumonia and age- and sex-matched healthy controls (total $\mathrm{N}=669$ ). Children are being followed in ongoing prospective work with respiratory phenotyping, including lung function measured by IOS at child age four years. The current analyses include a convenience sample of $\mathrm{N}=112$ children without respiratory symptoms at the time of nasopharyngeal swab and who successfully performed IOS at child age four years.

\subsection{Nasopharyngeal Microbiota Sampling and $P C R$}

As above, NPM swabs were collected in infants with and without respiratory symptoms. These analyses include only children with no respiratory symptoms at time of swab and who did not have a physician-diagnosed pneumonia episode within two weeks prior to or following swab collection. As previously described, swabs were stored at $-80{ }^{\circ} \mathrm{C}$ until analysis; all samples were shipped from Ghana to the United States on dry ice with internal temperature monitors. We employed MassTag polymerase chain reaction (PCR) to identify the presence of 22 common bacterial and viral respiratory pathogens (see Table S1) [27]. We extracted total nucleic acid (TNA) from $200 \mathrm{~mL}$ of each nasal swab using the EasyMag Extraction Platform (Biomerieux, Marcy l'Etoile, France). TNA was eluted in $40 \mathrm{~mL}$. Ten $\mathrm{mL}$ of TNA DNA was used to generate cDNA. TNA or cDNA ( $5 \mathrm{~mL}$ per reaction) was then used as a template for MassTag PCR using two separate PCR multiplex assays. The first PCR multiplex assay targeted common respiratory RNA viruses with cDNA as the template. The second targeted bacterial agents and adenovirus using TNA as the template. PCR and agent detection were performed as previously described [36].

\subsection{Impulse Oscillometry (IOS) Lung Function Testing}

Lung function was measured in the children at four years of age by a trained study pediatrician using impulse oscillometry (IOS) (Masterscreen IOS, Carefusion, San Diego, CA, USA) following American Thoracic Society guidelines [37-39]. Eligible participants were free from respiratory symptoms for at least three weeks. IOS requires that a participant perform tidal breathing into a mouthpiece for 30 seconds and therefore, contrary to spirometry, is not reliant on participant effort and can be reliably performed in young children. The IOS system was calibrated each day immediately prior to measurements using a standard 3-liter syringe. The participants performed IOS in a standing position and wearing a nose clip with cheeks supported by a trained research assistant. The supervising 
pediatrician evaluated efforts and made sure that each valid study included at least three reproducible measures free from artifact. The Masterscreen LabManager calculated $R_{\mathrm{rs}}$ and $X_{\mathrm{rs}}$ and reported resistance at $5 \mathrm{~Hz}(\mathrm{R} 5)$, reactance at $5 \mathrm{~Hz}(\mathrm{X} 5)$, resistance at $20 \mathrm{~Hz}$ (R20), the difference in resistance at 5 and $20 \mathrm{~Hz}$ (R5-20), reactance area (AX), and resonant frequency (Fres). Mean values from the three valid trials were used in analyses.

\subsection{Covariates}

Maternal education, parity, secondhand smoke exposure (defined as having a household member who smoked), ethnicity, and number of persons living in the household were the categorical variables obtained via questionnaire at study enrollment. Child sex and date of birth were recorded at delivery. Age at time of NPM swab was determined by the difference between date of NPM swab and date of delivery. Child height and weight were measured at the time of lung function testing.

\subsection{Statistical Analysis}

First, we performed a latent class analysis of the NPM PCR data to identify the number of subphenotypes of pathogens, considering two to five classes. Criteria for model selection, where the number of subphenotypes defines the model, included Akaike information criterion (AIC) and Bayesian information criterion (BIC), where smaller values suggest better fit; entropy, range 0 to 1 where higher values indicate better class separation; and subphenotype class size, where classes with small numbers would not be beneficial [40]. Once the optimal number of subphenotypes was identified, participants were assigned to the subphenotype for which they had the highest probability of correct assignment. These NPM subphenotype assignments were then used as the independent variable for subsequent regression analyses.

We employed bivariate and multivariable linear regression to determine associations between the identified subphenotypes and IOS variables. Secondary analyses included exploring whether specific pathogens drove any identified associations with IOS variables. Multivariable models were adjusted for child sex, height, age at NPM swab, time between NPM swab and lung function, and maternal education. Sensitivity analyses additionally adjusted for parity, secondhand smoke exposure, number of people living in the household, race/ethnicity, and child BMI.

\subsection{Internal Review Board Approval}

IRB approval was obtained from the Icahn School of Medicine Mount Sinai, Columbia University, and Ghana Interval Review Boards.

\section{Results}

Of the 112 children included in the study, $n=57(50.9 \%)$ were male (Table 1$)$. Children were a median age of 4.27 (IQR 2.86, 7.11) months at the time of NPM swab with a median time of 3.57 (IQR 3.37, 3.70) years between swab and lung function. Only $11(9.8 \%)$ mothers reported secondhand smoke exposure. Of the 22 possible pathogens on the PCR panel, $12(54.5 \%)$ were detected in this population. The most commonly detected pathogens were Streptococcus pneumonia $(n=83,74.1 \%)$, enterovirus/rhinovirus $(n=69,61.6 \%)$, Moraxella cattarhalis $(n=68,60.7 \%)$, Haemophilus influenza $(n=54,48.2 \%)$, and human parainfluenza virus $3(n=21,18.8 \%)$. A median of three (IQR 2, 4) pathogens were detected per participant, with a range from zero to five. A median of two (IQR 1,3) bacteria and one (IQR 0,1) virus were detected per participant. 
Table 1. Participant characteristics $(n=112)$.

\begin{tabular}{lcc}
\hline & Number & Percent \\
\hline Child sex, Male & 57 & 50.9 \\
Secondhand smoke exposure, Yes & 11 & 9.8 \\
& Median & IQR \\
\hline Height (m) & 0.98 & $0.95,1.01$ \\
Number of people in household & 6 & 5,8 \\
Parity & 3 & 1,5 \\
Age at nasal swab (months) & 4.27 & $2.86,7.11$ \\
Number of pathogens detected on PCR & & \\
$\quad$ Bacteria & 2 & 1,3 \\
Viruses & 1 & 0,1 \\
\hline Age 4 Impulse Oscillometry (IOS) & & \\
\hline R5Hz [cmH2O/(L/s)] & 1.40 & $1.19,1.65$ \\
R20Hz [cmH2O/(L/s)] & 0.83 & $0.72,0.97$ \\
R5-20 (\%) & 66.4 & $50.1,96.9$ \\
X5 [cmH2O/(L/s)] & -0.32 & $-0.41,-0.20$ \\
Fres (1/s) & 27.8 & $23.9,34.5$ \\
AX (cmH2O/L) & 5.60 & $4.37,7.27$ \\
CO20Hz & 0.94 & $0.90,0.95$ \\
Time from nasal swab to IOS (Years) & 3.57 & $3.37,3.70$ \\
\hline
\end{tabular}

$\overline{\mathrm{PCR}}=$ polymerase chain reaction.

\subsection{Latent Class Analysis}

We performed latent class analyses and fit models with two through five subphenotypes to determine the optimal number of NPM subphenotypes in this population (Table 2). Using AIC, BIC, and number of participants per class, we determined the optimal fit of NPM subphenotypes was two classes. A less diverse subphenotype $(n=74)$ was identified and characterized by having fewer pathogens (median 2; IQR 1,3) and specifically fewer bacteria (median 1; IQR 1, 2) (Table S2). A more diverse subphenotype $(n=38)$ was characterized by having more pathogens (median 4; IQR $3.25,4.75$ ) and specifically more bacteria with $34 / 38$ participants in this class having three detectable bacteria and 4/38 participants having two detectable bacteria.

Table 2. Fit statistics for latent class analysis demonstrating a two-class model as the best fit for this cohort.

\begin{tabular}{|c|c|c|c|c|c|c|c|c|}
\hline \multirow[t]{2}{*}{ Number of Classes } & \multirow[t]{2}{*}{ AIC } & \multirow[t]{2}{*}{ BIC } & \multirow[t]{2}{*}{ Entropy } & \multicolumn{5}{|c|}{ Number of Individuals in Each Class } \\
\hline & & & & 1 & 2 & 3 & 4 & 5 \\
\hline \multicolumn{9}{|l|}{ Nasal PCR } \\
\hline \multicolumn{9}{|l|}{ Number of Classes } \\
\hline 1 & 873 & 905 & 3.7 & 112 & & & & \\
\hline 2 & 841 & 908 & 3.6 & 38 & 74 & & & \\
\hline 3 & 878 & 982 & 3.6 & 44 & 52 & 16 & & \\
\hline 4 & 900 & 1039 & 3.6 & 42 & 27 & 41 & 2 & \\
\hline 5 & 889 & 1061 & 3.5 & 11 & 25 & 32 & 42 & 2 \\
\hline
\end{tabular}

$\overline{\mathrm{AIC}}=$ Akaike information criterion. $\mathrm{BIC}=$ Bayesian information criterion.

\subsection{Linear Regression}

Examination of the associations between NPM subphenotypes suggested that children with the more diverse subphenotype had no change in total airway resistance $(\mathrm{R} 5 \mathrm{~Hz} \beta=0.03 \mathrm{cmH} 2 \mathrm{O} /(\mathrm{L} / \mathrm{s}), 95 \% \mathrm{CI}-0.16,0.21 ; p=0.76)$ but an increase in large airway resistance $(\mathrm{R} 20 \mathrm{~Hz} \beta=0.11 \mathrm{cmH} 2 \mathrm{O} /(\mathrm{L} / \mathrm{s}), 95 \% \mathrm{CI} 0.02,0.20 ; p=0.02)$ and a decrease in small airway resistance (R5-20 $\beta=-17.9 \%, 95 \% \mathrm{CI}-35.6,-0.23 ; p=0.047$ ) compared with the less diverse phenotype following adjustment for child sex and height, maternal 
education, age at time of swab, and time between swab and lung function testing (Table 3). Sensitivity models additionally adjusting for parity, secondhand smoke exposure, number of people in the household, ethnicity, and child BMI did not substantively change these findings (Table S3).

Table 3. Associations between nasopharyngeal microbiota (NPM) subphenotypes and impulse oscillometry (IOS).

\begin{tabular}{lcccc}
\hline \multirow{2}{*}{ IOS Parameters } & \multicolumn{2}{c}{ Unadjusted Model } & \multicolumn{2}{c}{ Adjusted Model * } \\
\cline { 2 - 5 } & $\boldsymbol{\beta}(\mathbf{9 5 \%} \mathbf{C I})$ & $\boldsymbol{p}$ & $\boldsymbol{\beta} \mathbf{( 9 5 \% \mathbf { C I } )}$ & $\boldsymbol{p}$ \\
\hline $\mathrm{R} 5 \mathrm{~Hz}[\mathrm{cmH} 2 \mathrm{O} / \mathrm{L} / \mathrm{s})]$ & $0.02(-0.16,0.20)$ & 0.82 & $0.03(-0.16,0.21)$ & 0.76 \\
$\mathrm{X} 5 \mathrm{~Hz}[\mathrm{cmH} 2 \mathrm{O} / \mathrm{L} / \mathrm{s})]$ & $0.02(-0.08,0.11)$ & 0.76 & $-0.01(-0.10,0.09)$ & 0.91 \\
$\mathrm{R} 20 \mathrm{~Hz}[\mathrm{cmH} 2 \mathrm{O} / \mathrm{L} / \mathrm{s})]$ & $0.10(0.01,0.19)$ & 0.03 & $0.11(0.02,0.20)$ & 0.02 \\
$\mathrm{R} 5-\mathrm{R} 20(\%)$ & $-18.1(-34.9,-1.26)$ & 0.04 & $-17.9(-35.6,-0.23)$ & 0.047 \\
Fres $(1 / \mathrm{s})$ & $1.48(-1.86,4.83)$ & 0.38 & $1.32(-2.10,4.74)$ & 0.45 \\
$\mathrm{AX}(\mathrm{cmH} 2 \mathrm{O} / \mathrm{L})$ & $0.57(-0.44,1.57)$ & 0.27 & $0.65(-0.39,1.70)$ & 0.22 \\
\hline
\end{tabular}

* Model adjusted for child sex and height, maternal education; age at NPM PCR swab and time between NPM PCR swab and lung function testing. Beta interpreted as the difference in IOS variable between the more diverse subphenotype compared with to the less diverse subphenotype.

We then explored associations between the four most commonly PCR-detected pathogens, specifically Streptococcus pneumoniae, enterovirus/rhinovirus, Moraxella catarrhalis and Haemophilus influenzae, each considered separately, and IOS variables (Table 4). These exploratory analyses suggest that presence of colonization with enterovirus/rhinovirus and Moraxella catarrhalis may be associated with a trend to decreased R5-20 ( $\beta=-16.1 \%, 95 \%$ CI $-33.9,1.7 ; p=0.07$ and $\beta=-15.3 \%, 95 \% \mathrm{CI}-32.1,1.5 ; p=0.07)$. Detection of enterovirus / rhinovirus was also associated with a trend to increased $\mathrm{R} 20 \mathrm{~Hz}(\beta=0.08 \mathrm{cmH} 2 \mathrm{O} /(\mathrm{L} / \mathrm{s}), 95 \%$ CI $-0.01,0.18 ; p=0.08)$. Detection of Moraxella catarrhalis was also associated with increased Fres $(\beta=3.631 / \mathrm{s}, 95 \%$ CI 0.46, 6.79; $p=0.03)$ and Haemophilus influenzae was associated with increased AX ( $\beta=1.16 \mathrm{cmH} 2 \mathrm{O} / \mathrm{L}, 95 \%$ CI 0.16, 2.16; $p=0.02)$.

Table 4. Associations between specific nasopharyngeal pathogens and impulse oscillometry (IOS) *

\begin{tabular}{|c|c|c|c|c|}
\hline \multirow{2}{*}{ IOS Parameters } & \multicolumn{2}{|c|}{ Streptococcus pneumoniae } & \multicolumn{2}{|c|}{ Enterovirus/Rhinovirus } \\
\hline & $\beta(95 \% \mathrm{CI})$ & $p$ & $\beta(95 \% \mathrm{CI})$ & $p$ \\
\hline $\mathrm{R} 5 \mathrm{~Hz}[\mathrm{cmH} 2 \mathrm{O} /(\mathrm{L} / \mathrm{s})]$ & $-0.14(-0.34,0.06)$ & 0.16 & $-0.02(-0.21,0.16)$ & 0.83 \\
\hline $\mathrm{X} 5 \mathrm{~Hz}[\mathrm{cmH} 2 \mathrm{O} /(\mathrm{L} / \mathrm{s})]$ & $0.01(-0.10,0.11)$ & 0.90 & $0.04(-0.06,0.13)$ & 0.43 \\
\hline $\mathrm{R} 20 \mathrm{~Hz}[\mathrm{cmH} 2 \mathrm{O} /(\mathrm{L} / \mathrm{s})]$ & $-0.01(-0.12,0.09)$ & 0.80 & $0.08(-0.01,0.18)$ & 0.08 \\
\hline R5-R20 (\%) & $-11.5(-31,7.95)$ & 0.24 & $-16.1(-33.9,1.7)$ & 0.07 \\
\hline Fres $(1 / \mathrm{s})$ & $0.11(-3.62,3.84)$ & 0.95 & $1.76(-1.67,5.20)$ & 0.31 \\
\hline \multirow[t]{3}{*}{$\mathrm{AX}(\mathrm{cmH} 2 \mathrm{O} / \mathrm{L})$} & $0.21(-0.94,1.36)$ & 0.72 & $0.06(-0.99,1.12)$ & 0.91 \\
\hline & \multicolumn{2}{|c|}{ Moraxella catarrhalis } & \multicolumn{2}{|c|}{ Haemophilus influenzae } \\
\hline & $\beta(95 \% \mathrm{CI})$ & $p$ & $\beta(95 \% \mathrm{CI})$ & $p$ \\
\hline $\mathrm{R} 5 \mathrm{~Hz}[\mathrm{cmH} 2 \mathrm{O} /(\mathrm{L} / \mathrm{s})]$ & $-0.02(-0.19,0.15)$ & 0.81 & $0.02(-0.16,0.20)$ & 0.84 \\
\hline $\mathrm{X} 5 \mathrm{~Hz}[\mathrm{cmH} 2 \mathrm{O} /(\mathrm{L} / \mathrm{s})]$ & $0.02(-0.07,0.11)$ & 0.65 & $-0.07(-0.16,0.02)$ & 0.12 \\
\hline $\mathrm{R} 20 \mathrm{~Hz}[\mathrm{cmH} 2 \mathrm{O} /(\mathrm{L} / \mathrm{s})]$ & $0.06(-0.03,0.15)$ & 0.21 & $0.06(-0.04,0.15)$ & 0.24 \\
\hline R5-R20 (\%) & $-15.3(-32.1,1.5)$ & 0.07 & $-1.79(-19.6,16.0)$ & 0.84 \\
\hline Fres $(1 / \mathrm{s})$ & $3.63(0.46,6.79)$ & 0.03 & $0.92(-2.46,4.30)$ & 0.59 \\
\hline $\mathrm{AX}(\mathrm{cmH} 2 \mathrm{O} / \mathrm{L})$ & $0.48(-0.50,1.46)$ & 0.33 & $1.16(0.16,2.16)$ & 0.02 \\
\hline
\end{tabular}

* All models adjusted for child sex and height, maternal education, age at NPM swab, and time between NPM swab and lung function testing. Beta interpreted as the difference in the IOS variable between those with detected indicated pathogen compared with undetected. 


\section{Discussion}

Impaired lung function and lung growth in childhood is a major risk factor for chronic respiratory disease over the life course. These analyses leverage a pregnancy cohort from rural sub-Saharan Africa with nasopharyngeal microbiota swabs from healthy infants and subsequent early childhood lung function as measured by impulse oscillometry and suggest that a less diverse respiratory microbiota in infancy is associated with increased small airway resistance in early childhood-a finding typically seen in asthma and other obstructive respiratory diseases. These results build on existing data from high-income countries and are a first step in elucidating mechanistic pathways that may increase risk for poorer lung health in a rural sub-Saharan population.

These data extend emerging evidence of the importance of respiratory microbiota on early life lung health, specifically lung function, and in a rural sub-Saharan African cohort relate microbiota carriage in infancy to future lung health. Once considered sterile, bacterial and viral colonization of the lungs has been demonstrated in children and infants [24,41]. In our study, targeted PCR of nasopharyngeal swabs in healthy infants found colonization with 12 unique bacteria and viruses. The four most commonly identified pathogens, Streptococcus pneumoniae, Haemophilus influenzae, enterovirus/rhinovirus, and Moraxella catarrhalis, were similar to those reported in the literature $[14,15,19,20,24,42,43]$. Other pathogens frequently discussed in studies, Staphylococcus, and Cornebacteriacae species, were not included in this PCR test and therefore their prevalence is unknown in our population. Respiratory syncytial virus and influenza $A$, which are frequently reported in other studies, were not found in this population, but given these pathogens frequently cause symptoms, it is not surprising they were not detected in our asymptomatic cohort. While this is not a comprehensive study of the microbiome, we did find polymicrobial colonization was present based on our PCR test, in the majority of infants in this cohort with a median of three (IQR 2, 4) pathogens present by age 4.3 months (IQR 2.9, 7.1).

These data suggest that lower NPM diversity in infancy is associated with increased small airway resistance. Increases in small airway resistance, as demonstrated by increased R5-20, are associated with asthma and increased risk of asthma exacerbations [44-46]. An increased AX, or total reactance, a measure of the change in the degree peripheral airway obstruction, has also been associated with asthma and an increased risk of losing asthma control in the subsequent 2-3 months [38,44,46]. A higher resonant frequency (Fres), the point at which the capacitive and inertive pressures in the lung equalize, is also associated with obstructive lung diseases, such as asthma, and restrictive lung diseases [44]. Overall, we find that a more diverse NPM subphenotype is associated with lower small airway resistance. Analyses of individual pathogens supported these findings. However, Haemophilus influenzae and Moraxella catarrhalis were also associated with increased AX and Fres, respectively. Continued follow up of lung health in this cohort is needed to understand the long-term lung health implications of these findings.

Studies from high-income countries support the importance of respiratory microbiota in the development of pulmonary disease. For example, respiratory microbiome colonization with Streptococcus pneumonia, Haemophilus influenzae and, in some studies, Moraxella cattarhalis has been associated with wheeze and asthma exacerbations [42,43]. Colonization in infancy is likely important. Bisgaard and colleagues demonstrated that neonatal colonization with these pathogens was associated with worse bronchodilator response at age five years, supporting our finding that respiratory microbiota can have a longstanding impact on lung function [24]. Our data suggests that a more diverse microbiota subphenotype in infancy was associated with lower resistance in the small airways, suggesting a possible protective effect. Interestingly, exploratory analyses of individual pathogens on child lung function showed trends but not similar effects. The bacteria and viruses that compose the microbiota do not exist in isolation and these analyses highlight the importance of employing analytic techniques that allow consideration of multiple, or the mixture of, microbes. A synergistic effect of microbes is likely important; it is possible 
that it is not a single pathogen, but rather the balance of respiratory microbiota, or overall diversity, that is essential.

Contrary to reports from high-income countries, the more diverse subphenotype identified in our cohort was characterized by the presence of Streptococcus, Haemophilus and Moraxella species-pathogens that in prior literature have been associated with wheeze and the development of asthma. Exploratory linear regressions demonstrated that enterovirus/rhinovirus and Moraxella species may drive this association. However, there are a number of differences between our population and those reported in prior literature which may contribute to these differences. The respiratory microbiome is shaped by many individual- and household-level factors, including mode of delivery, breastfeeding, number of siblings, and environmental exposures including air pollution and proximity to livestock to name a few $[15,16,20,24,47,48]$. For many of these variables, our population was homogeneous-for example, all households are agrarian with exposure to livestock, all children received pneumococcal vaccinations, and all children were breastfed through the first year of life. Given differences in our rural Ghanaian cohort and those cohorts reported from high-income countries, differences in microbiota and associations with respiratory phenotype are not surprising but do require confirmation and additional evaluation. Future work should also investigate whether these microbiota and lung function findings early in life will persist into adulthood.

Our study has several strengths. First, we leverage a prospective pregnancy cohort from rural sub-Saharan Africa, a population whose microbiota and respiratory phenotype has not previously been described. We assessed microbiota in healthy infants, prospectively collected data on important covariates, and employed a validated measure of lung function in early childhood. We applied a data-driven method to assess the microbiota mixture, allowing us to identify an underlying subphenotype as well as associations between these subphenotypes and future lung function. Our well-characterized cohort allowed for adjustment for a number of important covariates and a broad range of sensitivity analyses. As we continue to follow our cohort as they age, it will be important to repeat microbiota assessments and lung function to determine continued associations and whether microbiota in infancy can serve as a biomarker of future child respiratory health outcomes.

We also acknowledge limitations. We sampled the nasopharyngeal microbiota once in infancy, capturing one time point in a dynamic system. We limited our sample to asymptomatic infants at time of swab and without a pneumonia diagnosis within two weeks prior to or following swab to ensure a recent infection or course of antibiotics did not cause an acute change in the respiratory microbiota. However, it is possible that we were unable to detect clinically mild respiratory infections which could, in turn, transiently alter the microbiota. Additionally, the PCR analyses were limited to 22 common pathogens and did not provide a comprehensive assessment of all pathogens present in the nasopharyngeal microbiota or a full assessment of the microbiome. Other methods, including shotgun metagenomics, would provide a more complete picture of the nasopharyngeal microbiome and enable a better understanding of the diversity in our cohort. A larger sample size may have allowed us to detect additional subphenotypes and explore higher-level interactions, for example, sex-specific differences. Finally, our findings from a rural Ghanaian cohort may not be broadly generalizable.

\section{Conclusions}

These data from a rural Ghanaian cohort suggest an association between infant respiratory microbiota subphenotypes and future lung function, adding to the growing body of literature supporting the importance of the early life microbiome in future health. Further studies are required to replicate and extend these findings.

Supplementary Materials: The following are available online at https:/ /www.mdpi.com/article/10 .3390 /ijerph18147276/s1, Table S1: Bacterial and viral pathogens tested on PCR, Table S2: Detected rate of pathogens by PCR, Table S3: Sensitivity analysis: Associations between nasopharyngeal microbiota (NPM) subphenotypes and impulse oscillometry (IOS). 
Author Contributions: A.G.L., D.J. and K.P.A. conceived of the study and oversaw implementation; K.D., K.P.A., A.G.L. and D.J. led data analysis and manuscript writing; S.K., R.K.D.P., T.T., M.M. and K.P.A. led lung function assessment teams; and S.K., R.K.D.P., T.T., M.M., L.I., D.G.K., O.A., F.M.K., S.O.-O. and K.P.A. oversaw daily field operations. K.D., S.K., D.J., R.K.D.P., J.C.C., T.T., M.M., L.I., D.C., D.G.K., O.A., F.M.K., S.O.-O., A.G.L., K.P.A. assisted with data interpretation, manuscript preparation, and final manuscript review. All authors have read and agreed to the published version of the manuscript.

Funding: The GRAPHS cohort is supported by R01 ES026991, R01 ES019547, R21 TW010957, a Mailman School of Public Health Dean's Pilot Award and a child survival grant from the Clean Cooking Alliance. AGL was supported by K23 HL135349.

Institutional Review Board Statement: The study was conducted according to the guidelines of the Declaration of Helsinki, and approved by the Institutional Review Board of Icahn School of Medicine Mount Sinai (17-01265), Columbia University (AAAR4373) and the Ghana Internal Review Board (0004854).

Informed Consent Statement: Informed consent was obtained from all subjects involved in the study.

Data Availability Statement: The de-identified data presented in this study is available on request from the corresponding author.

Conflicts of Interest: The authors declare no conflict of interest. The funders had no role in the design of the study; in the collection, analyses, or interpretation of data; in the writing of the manuscript, or in the decision to publish the results.

\section{References}

1. United Nations Inter-agency Group for Child Mortality Estimation (UN IGME). Levels E Trends in Child Mortality: Report 2019, Estimates Developed by the United Nations Inter-Agency Group for Child Mortality Estimation; United Nations Children's Fund: New York, NY, USA, 2019.

2. Lee, A.G.; Kaali, S.; Quinn, A.; Delimini, R.; Burkart, K.; Opoku-Mensah, J.; Wylie, B.J.; Yawson, A.K.; Kinney, P.L.; Ae-Ngibise, K.A.; et al. Prenatal Household Air Pollution Is Associated with Impaired Infant Lung Function with Sex-Specific Effects. Evidence from GRAPHS, a Cluster Randomized Cookstove Intervention Trial. Am. J. Respir. Crit. Care Med. 2019, 199, 738-746. [CrossRef]

3. Gray, D.M.; Turkovic, L.; Willemse, L.; Visagie, A.; Vanker, A.; Stein, D.J.; Sly, P.D.; Hall, G.L.; Zar, H.J. Lung Function in African Infants in the Drakenstein Child Health Study. Impact of Lower Respiratory Tract Illness. Am. J. Respir. Crit. Care Med. 2017, 195, 212-220. [CrossRef]

4. Grad, R.; Morgan, W.J. Long-term outcomes of early-onset wheeze and asthma. J. Allergy Clin. Immunol. 2012, 130, 299-307. [CrossRef] [PubMed]

5. Morgan, W.J.; Stern, D.A.; Sherrill, D.L.; Guerra, S.; Holberg, C.J.; Guilbert, T.W.; Taussig, L.M.; Wright, A.L.; Martinez, F.D. Outcome of asthma and wheezing in the first 6 years of life: Follow-up through adolescence. Am. J. Respir. Crit. Care Med. 2005, 172, 1253-1258. [CrossRef]

6. Sears, M.R.; Greene, J.M.; Willan, A.R.; Wiecek, E.M.; Taylor, D.R.; Flannery, E.M.; Cowan, J.O.; Herbison, G.P.; Silva, P.A.; Poulton, R. A longitudinal, population-based, cohort study of childhood asthma followed to adulthood. N. Engl. J. Med. 2003, 349, 1414-1422. [CrossRef] [PubMed]

7. Phelan, P.D.; Robertson, C.F.; Olinsky, A. The Melbourne Asthma Study: 1964-1999. J. Allergy Clin. Immunol. 2002, 109, 189-194. [CrossRef] [PubMed]

8. Lowe, L.A.; Simpson, A.; Woodcock, A.; Morris, J.; Murray, C.S.; Custovic, A. Wheeze phenotypes and lung function in preschool children. Am. J. Respir. Crit. Care Med. 2005, 171, 231-237. [CrossRef] [PubMed]

9. Lowe, L.; Murray, C.S.; Custovic, A.; Simpson, B.M.; Kissen, P.M.; Woodcock, A. Specific airway resistance in 3-year-old children: A prospective cohort study. Lancet 2002, 359, 1904-1908. [CrossRef]

10. Illi, S.; von Mutius, E.; Lau, S.; Niggemann, B.; Gruber, C.; Wahn, U. Perennial allergen sensitisation early in life and chronic asthma in children: A birth cohort study. Lancet 2006, 368, 763-770. [CrossRef]

11. Henderson, J.; Granell, R.; Heron, J.; Sherriff, A.; Simpson, A.; Woodcock, A.; Strachan, D.P.; Shaheen, S.O.; Sterne, J.A. Associations of wheezing phenotypes in the first 6 years of life with atopy, lung function and airway responsiveness in midchildhood. Thorax 2008, 63, 974-980. [CrossRef] [PubMed]

12. Dickson, R.P.; Martinez, F.J.; Huffnagle, G.B. The role of the microbiome in exacerbations of chronic lung diseases. Lancet 2014, 384, 691-702. [CrossRef]

13. O'Dwyer, D.N.; Dickson, R.P.; Moore, B.B. The Lung Microbiome, Immunity, and the Pathogenesis of Chronic Lung Disease. J. Immunol. 2016, 196, 4839-4847. [CrossRef] [PubMed] 
14. Salter, S.; Turner, C.; Watthanaworawit, W.; de Goffau, M.C.; Wagner, J.; Parkhill, J.; Bentley, S.D.; Goldblatt, D.; Nosten, F.; Turner, P. A longitudinal study of the infant nasopharyngeal microbiota: The effects of age, illness and antibiotic use in a cohort of South East Asian children. PLoS Negl. Trop. Dis. 2017. [CrossRef] [PubMed]

15. Bosch, A.; de Steenhuijsen Piters, W.A.A.; van Houten, M.A.; Chu, M.; Biesbroek, G.; Kool, J.; Pernet, P.; de Groot, P.C.M.; Eijkemans, M.J.C.; Keijser, B.J.F.; et al. Maturation of the Infant Respiratory Microbiota, Environmental Drivers, and Health Consequences. A Prospective Cohort Study. Am. J. Respir. Crit. Care Med. 2017, 196, 1582-1590. [CrossRef] [PubMed]

16. Ta, L.D.H.; Yap, G.C.; Tay, C.J.X.; Lim, A.S.M.; Huang, C.-H.; Chu, C.W.; De Sessions, P.F.; Shek, L.P.; Goh, A.; Van Bever, H.P.S.; et al. Establishment of the nasal microbiota in the first 18 months of life: Correlation with early-onset rhinitis and wheezing. J. Allergy Clin. Immunol. 2018, 142, 86-95. [CrossRef]

17. Al Alam, D.; Danopoulos, S.; Grubbs, B.; Ali, N.; MacAogain, M.; Chotirmall, S.H.; Warburton, D.; Gaggar, A.; Ambalavanan, N.; Lal, C.V. Human Fetal Lungs Harbor a Microbiome Signature. Am. J. Respir. Crit. Care Med. 2020, 201, 1002-1006. [CrossRef] [PubMed]

18. Bosch, A.; Levin, E.; van Houten, M.A.; Hasrat, R.; Kalkman, G.; Biesbroek, G.; de Steenhuijsen Piters, W.A.A.; de Groot, P.C.M.; Pernet, P.; Keijser, B.J.F.; et al. Development of Upper Respiratory Tract Microbiota in Infancy is Affected by Mode of Delivery. EBioMedicine 2016, 9, 336-345. [CrossRef]

19. Biesbroek, G.; Tsivtsivadze, E.; Sanders, E.A.; Montijn, R.; Veenhoven, R.H.; Keijser, B.J.; Bogaert, D. Early respiratory microbiota composition determines bacterial succession patterns and respiratory health in children. Am. J. Respir. Crit. Care Med. 2014, 190, 1283-1292. [CrossRef]

20. Teo, S.M.; Mok, D.; Pham, K.; Kusel, M.; Serralha, M.; Troy, N.; Holt, B.J.; Hales, B.J.; Walker, M.L.; Hollams, E.; et al. The infant nasopharyngeal microbiome impacts severity of lower respiratory infection and risk of asthma development. Cell Host Microbe 2015, 17, 704-715. [CrossRef] [PubMed]

21. Man, W.H.; van Houten, M.A.; Mérelle, M.E.; Vlieger, A.M.; Chu, M.L.J.N.; Jansen, N.J.G.; Sanders, E.A.M.; Bogaert, D. Bacterial and viral respiratory tract microbiota and host characteristics in children with lower respiratory tract infections: A matched case-control study. Lancet Respir. Med. 2019, 7, 417-426. [CrossRef]

22. Folsgaard, N.V.; Schjorring, S.; Chawes, B.L.; Rasmussen, M.A.; Krogfelt, K.A.; Brix, S.; Bisgaard, H. Pathogenic bacteria colonizing the airways in asymptomatic neonates stimulates topical inflammatory mediator release. Am. J. Respir. Crit. Care Med. 2013, 187, 589-595. [CrossRef]

23. Hilty, M.; Burke, C.; Pedro, H.; Cardenas, P.; Bush, A.; Bossley, C.; Davies, J.; Ervine, A.; Poulter, L.; Pachter, L.; et al. Disordered microbial communities in asthmatic airways. PLoS ONE 2010, 5, e8578. [CrossRef]

24. Bisgaard, H.; Hermansen, M.N.; Buchvald, F.; Loland, L.; Halkjaer, L.B.; Bonnelykke, K.; Brasholt, M.; Heltberg, A.; Vissing, N.H.; Thorsen, S.V.; et al. Childhood asthma after bacterial colonization of the airway in neonates. N. Engl. J. Med. 2007, 357, 1487-1495. [CrossRef] [PubMed]

25. Ederveen, T.H.A.; Ferwerda, G.; Ahout, I.M.; Vissers, M.; de Groot, R.; Boekhorst, J.; Timmerman, H.M.; Huynen, M.A.; van Hijum, S.; de Jonge, M.I. Haemophilus is overrepresented in the nasopharynx of infants hospitalized with RSV infection and associated with increased viral load and enhanced mucosal CXCL8 responses. Microbiome 2018, 6, 10. [CrossRef] [PubMed]

26. de Steenhuijsen Piters, W.A.; Heinonen, S.; Hasrat, R.; Bunsow, E.; Smith, B.; Suarez-Arrabal, M.C.; Chaussabel, D.; Cohen, D.M.; Sanders, E.A.; Ramilo, O.; et al. Nasopharyngeal Microbiota, Host Transcriptome, and Disease Severity in Children with Respiratory Syncytial Virus Infection. Am. J. Respir. Crit. Care Med. 2016, 194, 1104-1115. [CrossRef]

27. Carrión, D.; Kaali, S.; Kinney, P.L.; Owusu-Agyei, S.; Chillrud, S.; Yawson, A.K.; Quinn, A.; Wylie, B.; Ae-Ngibise, K.; Lee, A.G.; et al. Examining the relationship between household air pollution and infant microbial nasal carriage in a Ghanaian cohort. Environ. Int. 2019, 133, 105150. [CrossRef] [PubMed]

28. Faner, R.; Sibila, O.; Agusti, A.; Bernasconi, E.; Chalmers, J.D.; Huffnagle, G.B.; Manichanh, C.; Molyneaux, P.L.; Paredes, R.; Perez Brocal, V.; et al. The microbiome in respiratory medicine: Current challenges and future perspectives. Eur. Respir. J. 2017, 49. [CrossRef] [PubMed]

29. Depner, M.; Ege, M.J.; Cox, M.J.; Dwyer, S.; Walker, A.W.; Birzele, L.T.; Genuneit, J.; Horak, E.; Braun-Fahrlander, C.; Danielewicz, H.; et al. Bacterial microbiota of the upper respiratory tract and childhood asthma. J. Allergy Clin. Immunol. 2017, 139, 826-834.E13. [CrossRef]

30. Wostmann, B.S. The germfree animal in nutritional studies. Annu. Rev. Nutr. 1981, 1, 257-279. [CrossRef] [PubMed]

31. Yun, Y.; Srinivas, G.; Kuenzel, S.; Linnenbrink, M.; Alnahas, S.; Bruce, K.D.; Steinhoff, U.; Baines, J.F.; Schaible, U.E. Environmentally determined differences in the murine lung microbiota and their relation to alveolar architecture. PLOS ONE 2014, 9 , e113466. [CrossRef] [PubMed]

32. Carney, S.M.; Clemente, J.C.; Cox, M.J.; Dickson, R.P.; Huang, Y.J.; Kitsios, G.D.; Kloepfer, K.M.; Leung, J.M.; LeVan, T.D.; Molyneaux, P.L.; et al. Methods in Lung Microbiome Research. Am. J. Respir. Cell Mol. Biol. 2020, 62, 283-299. [CrossRef]

33. Morgan, X.C.; Huttenhower, C. Chapter 12: Human microbiome analysis. PLoS Comput. Biol. 2012, 8, e1002808. [CrossRef] [PubMed]

34. Marchesi, J.R.; Ravel, J. The vocabulary of microbiome research: A proposal. Microbiome 2015, 3, 31. [CrossRef]

35. Jack, D.W.; Asante, K.P.; Wylie, B.J.; Chillrud, S.N.; Whyatt, R.M.; Ae-Ngibise, K.A.; Quinn, A.K.; Yawson, A.K.; Boamah, E.A.; Agyei, O.; et al. Ghana randomized air pollution and health study (GRAPHS): Study protocol for a randomized controlled trial. Trials 2015, 16. [CrossRef] [PubMed] 
36. Briese, T.; Palacios, G.; Kokoris, M.; Jabado, O.; Liu, Z.; Renwick, N.; Kapoor, V.; Casas, I.; Pozo, F.; Limberger, R.; et al. Diagnostic system for rapid and sensitive differential detection of pathogens. Emerg. Infect. Dis. 2005, 11, 310-313. [CrossRef]

37. Beydon, N.; Davis, S.D.; Lombardi, E.; Allen, J.L.; Arets, H.G.; Aurora, P.; Bisgaard, H.; Davis, G.M.; Ducharme, F.M.; Eigen, H.; et al. An official American Thoracic Society/European Respiratory Society statement: Pulmonary function testing in preschool children. Am. J. Respir. Crit. Care Med. 2007, 175, 1304-1345. [CrossRef] [PubMed]

38. Komarow, H.D.; Skinner, J.; Young, M.; Gaskins, D.; Nelson, C.; Gergen, P.J.; Metcalfe, D.D. A study of the use of impulse oscillometry in the evaluation of children with asthma: Analysis of lung parameters, order effect, and utility compared with spirometry. Pediatric Pulmonol. 2012, 47, 18-26. [CrossRef] [PubMed]

39. Duenas-Meza, E.; Correa, E.; Lopez, E.; Morales, J.C.; Aguirre-Franco, C.E.; Morantes-Ariza, C.F.; Granados, C.E.; GonzalezGarcia, M. Impulse oscillometry reference values and bronchodilator response in three- to five-year old children living at high altitude. J. Asthma Allergy 2019, 12, 263-271. [CrossRef] [PubMed]

40. Muthén, B. Latent variable analysis. In The Sage Handbook of Quantitative Methodology for the Social Sciences; Kaplan, D., Ed.; SAGE Publications, Inc.: Thousand Oaks, CA, USA, 2004; pp. 346-369.

41. Van der Zalm, M.; Van Ewijk, B.E.; Wilbrink, B.; Uiterwaal, C.S.P.M.; Wolfs, T.F.W.; Van der Ent, C.K. Respiratory Pathogens in Children with and without Respiratory Symptoms. J. Pediatrics 2009, 154, 396-400. [CrossRef]

42. McCauley, K.; Durack, J.; Valladares, R.; Fadrosh, D.W.; Lin, D.L.; Calatroni, A.; Lebeau, P.K.; Tran, H.T.; Fujimura, K.E.; Lamere, B.; et al. Distinct Nasal Airway Bacterial Microbiota Differentially Relate to Exacerbation in Pediatric Asthma. J. Allergy Clin. Immunol. 2019. [CrossRef]

43. Shukla, S.D.; Budden, K.F.; Neal, R.; Hansbro, P.M. Microbiome effects on immunity, health and disease in the lung. Clin. Transl. Immunol. 2017, 6, e133. [CrossRef] [PubMed]

44. Brashier, B.; Salvi, S. Measuring lung function using sound waves: Role of the forced oscillation technique and impulse oscillometry system. Breathe 2015, 11,57-65. [CrossRef]

45. Schulze, J.; Biedebach, S.; Christmann, M.; Herrmann, E.; Voss, S.; Zielen, S. Impulse Oscillometry as a Predictor of Asthma Exacerbations in Young Children. Respiration 2016, 91, 107-114. [CrossRef] [PubMed]

46. Shi, Y.; Aledia, A.S.; Tatavoosian, A.V.; Vijayalakshmi, S.; Galant, S.P.; George, S.C. Relating small airways to asthma control by using impulse oscillometry in children. J. Allergy Clin. Immunol. 2012, 129, 671-678. [CrossRef] [PubMed]

47. Hakansson, A.P.; Orihuela, C.J.; Bogaert, D. Bacterial-Host Interactions: Physiology and Pathophysiology of Respiratory Infection. Physiol. Rev. 2018, 98, 781-811. [CrossRef]

48. Man, W.H.; de Steenhuijsen Piters, W.A.; Bogaert, D. The microbiota of the respiratory tract: Gatekeeper to respiratory health. Nat. Rev. Microbiol. 2017, 15, 259-270. [CrossRef] 